\title{
Population dynamics model of Euterpina acutifrons (Copepoda: Harpacticoida) coupling individual growth and larval development
}

\author{
François Carlotti, Antoine Sciandra
}

Station Zoologique, C.E.R.O.V., B.P. 28, U.A. 716, F-06230 Villefranche-sur-mer, France

\begin{abstract}
A mathematical model of population dynamics is proposed which embodies the principal biological processes involved in the energetic budget of Euterpina acutifrons Dana (Copepoda: Harpacticoida): ingestion, excretion, egestion, and reproduction. The model proposes functional connections between growth and development through the larval instars. The major hypotheses are: (1) weight and cumulated specific growth rate control the molting process; (2) molting occurs at fixed weights which are independent of temperature; (3) temperature influences only the ingestion process according to a constant $Q_{10}$ rule. Simulations fit satisfactorily with the development of E. acutifrons followed experimentally in different conditions of temperature and food concentration. Growth was sigmoidal, the major weight increase being between stage $\mathrm{C} 5$ and adult. The model reveals $\mathrm{Q}_{10}$ values for growth and development between 10 and $25^{\circ} \mathrm{C}$ which are constant and similar, and higher than the $Q_{10}$ for ingestion. According to the hypotheses put forward, growth is potentially exponential over a wide range of food and temperature. Equiproportional development was found for E, acutifrons. The model is used to test the effects of variation of food and predators on the recruitment of a population of E. acutifrons. Because of the number and nonlinearity of interactions between biological processes governing development, only a sophisticated model incorporating both physiological and developmental processes is able to predict the effect of simultaneous external forcing variables on the population success
\end{abstract}

\section{INTRODUCTION}

Numerous biological factors, such as food and predation, and physical factors, such as temperature, salinity and light, influence survival, reproduction and metabolic rates of copepods in culture (Marshall 1973, Corkett \& McLaren 1978, Paffenhöfer \& Harris 1979). Food and temperature are generally considered as the most important parameters of population dynamics and individual growth (Thompson 1982). Temperature influences mortality, instar duration (Haq 1972, McLaren 1978), molting rate (Heip 1974), and reproduction (Landry 1975). Food also plays an important role in mortality (Paffenhöfer 1970), instar duration (Vidal 1980b), and egg production (Zurlini et al. 1978). Often, these relations have been established in the laboratory which provides constant conditions for measurements. Only a few relationships have been estimated in situ, such as egg production (Dagg 1977). Based on this knowledge, models have been designed at different levels of complexity. The simplest show the influence of external parameters on a process involved in the dynamics such as developmental rate (Heip 1974) or egg production (Uye 1981). More sophisticated models include several processes and are based on a global representation of the population (Zurlini et al. 1978, Zurlini \& Ferrari 1979); they can discriminate instars (Wroblewski 1980, Davis 1984), or age classes (Sciandra 1986a).

Relations between forcing parameters and physiological functions, especially those which are directly related to the energetic balance equation of growth (ingestion, excretion, egestion, reproduction), have been extensively studied. Temperature influences these processes according to a constant $Q_{10}$ law in the range of natural variations (Nival et al. 1974, Ikeda 1985). Food concentration influences filtration (Frost 1972), ingestion (Mullin \& Brooks 1970b, Paffenhöfer 1971), egestion (Gaudy 1974), excretion and respiration (Nival et al. 1974), and consequently, the growth rate (Mullin \& Brooks 1970b). There are simple relationships which link processes with field parameters, such as filtration with food (Lam \& Frost 1976) or ingestion with food concentration (Lehman 1976, Bartram 1980). Others 
link one growth characteristic with external parameters, such as weight with food (Zurlini et al. 1978), size with food (Paffenhöfer 1970), size with temperature (McLaren 1978) or weight, respiration and excretion with temperature (Nival et al. 1974). More elaborated growth models simultaneously consider ingestion, egestion, excretion and respiration (Steele 1974, Huntley \& Boyd 1984, Wroblewski 1984, Wroblewski \& Richman 1987).

External variations affect organisms through several biological steps, so that relations between causes and effects are rarely simple. In models of larval dynamics, development rates and external parameters are generally linked by empirical relationships, which do not take into account the functional properties of the processes involved in the dynamics. As a consequence, the field of application of these general models is restricted, especially if the external conditions of temperature and food are highly variable.

Population dynamics and individual growth are 2 different approach levels for studying copepods in their natural environment. This explains the fact that dynamics (fluxes of individuals) and growth (fluxes of matter and energy) are often modelled separately, although the latter controls the former. It is clear that a synthetic representation of population dynamics taking into account the biological characteristics of individuals would be very profitable, because of the exchange of information between the 2 different levels of knowledge.

Elaborated models of population dynamics, which embody the crucial relationships between the lower and upper trophic levels, are also useful tools for the understanding of ecosystem behavior. Representation of population dynamics in the model of Steele \& Frost (1977) is not very specific since only flows of biomass were taken into account. Steele \& Mullin (1977) discussed the necessity to use the number of individuals rather than the biomass to support a good description of the population dynamics. However, their model allowed only a single mean growth rate for the whole population, so that they were forced to assume a stable population structure.

This paper presents the integration of both biomass and number criteria through a unique conceptual model. The aim of this model (which is applicable to several species of copepods) is to simulate copepod population dynamics (here Euterpina acutifrons) in different conditions of food and temperature, by taking into account the processes involved in individual growth. This functional synthesis allows us to discuss hypotheses about possible relations between the different growth processes (ingestion, egestion, excretion, oogenesis, etc.) and the processes which control the time course of abundance of individuals in each instar (mortality rate, molting rate, reproduction).

\section{MODEL CONCEPTUALIZATION}

We consider that the development of copepods may be divided into 2 levels. The first corresponds to the natural succession of development stages $i$ : eggs ( $i=$ 1), nauplii ( $i=2$ to 7 ), copepodites ( $i=8$ to 12 ) and aduits $(i=13)$. The second level corresponds to age classes in each instar. The number of age classes is high enough to allow the maximal duration in each instar. This division makes is possible to represent copepods of different ages and weights in a given stage. Larval dynamics within such a structure, explained in detail by Nival et al. (1988), is based on previous models (Davis 1984, Sciandra 1986a, b, Carlotti 1987).

The change in number of individuals in each age class during each unit of time is used to count age. External parameters (temperature, food) control the individual growth rate, and consequently the variation of weight. Weight and growth rate are state variables which control the molting process. We use 2 basic hypotheses to relate growth to development. The first is that individuals of an instar i may be transferred to instar $\mathrm{i}+1$ only if they have reached a sufficient weight, called the critical molting weight $\left(X_{i}\right)$. In other words, each stage of development is characterized by a period of growth bracketed by critical weights of entering and leaving this stage. McLaren (1986) observed this penomenon in Calanus finmarchicus during the spring generation. Harris (1983) considered in his growth model a structural weight and a storage weight, and assumed that molts occur at fixed structural weights. We also make this assumption for Euterpina acutifrons which has little ability to store material. For naupliar and first copepodite stages, the results of Paffenhöfer (1971), Burkill \& Kendall (1982) and Hamburger \& Boëtius (1987) illustrate that the mean weight range of a given instar does not overlap that of the previous or the next instar. An overlap has been observed for the C5 and adult instars (Vidal 1980a, Berggreen et al. 1988) with a noticeable diminution of the weight at low food concentrations. At different temperatures, overlaps occur only for the older stages (C4 to adult) of Acartia tonsa (Miller et al. 1977), Pseudocalanus sp. (Corkett \& McLaren 1978), Acartia clausi (Landry 1978) with a marked diminution of weights at the higher temperatures. Mullin \& Brooks $(1970 \mathrm{a}, \mathrm{b})$ stated that temperature has a limited influence on the quantity of ingested food necessary to reach a given instar. For some other species (Calanus pacificus, Calanus helgolandicus, Eudiaptomus graciloides), the mean weight of an instar is not strongly dependent on temperature (Pfaffenhöfer 1971, Vidal 1980b, Hamburger \& Boëtius 1987). We assume here that the critical molting weight is independent of the 


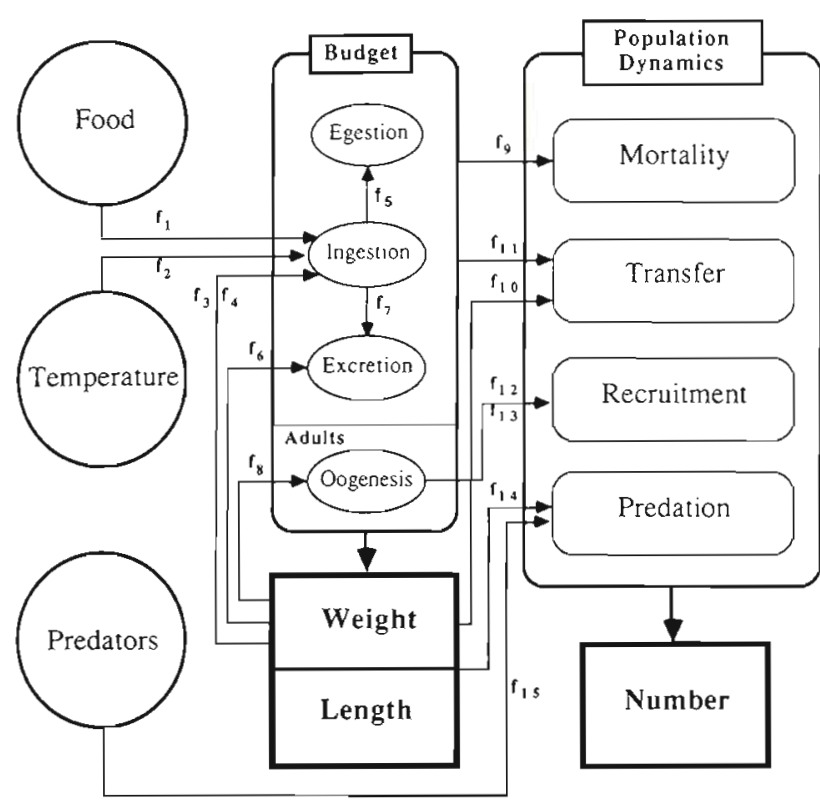

Fig. 1. Conceptual diagram of the model. Processes and variables are connected by arrows denoting relationships $f_{i}$ detailed in Table 1 and in the text. Note that the different dynamics terms are controlled by biological variables and processes involved in the energy budget, and not directly by the external forcing variables shown by circles on left

temperature and food conditions. As will be seen in the results, this assumption does not imply that instar mean weights are independent of food concentration and temperature. Moreover, this does not affect significantly the development rate.

The first hypothesis depends on the fact that molting is possible only if a sufficient amount of matter has been assimilated since the previous molt. The cumulated weight integrates the feeding history of the stage for several days.

The second hypotheses, proposed by Nival et al. (1988) depends on the assumption that molting is also controlled by the physiological state of larvae, which can be approximated by the specific growth rate (ratio of growth rate to weight). Changes in metabolic rate may limit molting even for larvae which have reached the critical molting weight. As the effects of external stimuli on growth are not instantaneous, it is necessary to take into account the feeding history of organisms during a preceding period of time so that variability of temperature and food can be damped. We consider here that the mean specific growth rate cumulated after some hours is the critical factor to be considered, instead of instantaneous specific growth rate.

The different biological processes controlling growth and population dynamics are presented in Fig. 1. Processes taken into account are presented in Tables 1 and 2. For each age class, 2 state variables represent the number $\left(N_{1, j}\right)$ and the weight $\left(W_{1, j}\right)$ of individuals.
Weight is controlled by growth, which depends on food and temperature, and both growth and weight control molting rate. Differential equations apply to each age class j of an instar i (Table 2).

The growth rate is expressed in nitrogen mass units. The ingestion rate of an instar $i$ is dependent firstly on the food concentration according to a sigmoidal function f1 (Sciandra 1982, 1986b), and secondly on temperature, following a constant $Q_{10}$ law $f 2$. We use the allometric relation expressed by Paffenhöfer (1971), f3, in which the maximal ingestion rate increases with weight during development.

Experimental studies have shown that some species of crustaceans with normal development stop eating just before and during the molting period (Lasker 1966, Paffenhöfer 1971, Harpaz et al. 1987). Harris \& Paffenhöfer (1976) observed in Temora longicornis a depression in feeding activity before molting to $\mathrm{C} 1$ and before the last molt to adult. Presumably ingestion decreases as weight reaches the critical weight of molt, because growth is limited by the exoskeleton. We assume that the ingestion of an instar follows a negative parabolic function $\mathrm{f} 4$ when the weight surpasses the critical molting weight. Such a limitation does not occur for adults for which reproduction limits weight increase.

Egested matter is the part of ingested matter which is not assimilated. We assume as a first approximation that assimilation efficiency is independent of the amount of ingested food (Conover 1966); the quantity of egested matter is simply proportional (f5) to the ingestion rate.

Metabolic rate is represented by excretion rate. We suppose as Wroblewski (1984) that excretion can be separated into 2 terms (see also Steele \& Mullin 1977. Vidal 1980c). The first (f6) represents the routine metabolism and is proportional to weight. The second (f7) refers to the active metabolism and is proportional to ingestion rate.

For mature adults, ingested matter is used for maintenance and reproduction (Sekiguchi et al. 1980). We assume that reproduction occurs when adults have accumulated a sufficient amount of matter. The relationship $f 8$ between the egg-laying rate and the nitrogen individual weight is sigmoidal. For crustaceans, such a relationship has been shown between the egglaying rate and the size or weight of females (Corkett \& McLaren 1969, Smith \& Lane 1985). Egg weight is considered here to be constant. The egg-laying rate per female (f12) is then equal to the ratio of the nitrogen mass invested for reproduction to the weight of an egg.

Mortality rate is usually considered constant for the whole population. This approximation neglects the facts that stages may have different sensitivity during critical periods such as molt or starvation, and that individuals in a given stage may have different mortal- 
Table 1. Mathematical formulations of relationships used in the model. i: stage; $j$ : age class. F: food; Te: temperature; $W_{1, j}$ : weight; $\mathrm{X}_{\mathrm{i}}$ : critical weight for transfer, $\mathrm{I}_{\mathrm{l}, 1}$ : ingestion; $\mathrm{SG}_{1,1}$ : specific growth; $\mathrm{CSG}_{i, j}$ : cumulated specific growth; Pr: predator density; c: capture rate coefficient; $\mathrm{P} 1_{1}$ to $\mathrm{P} 19_{1}$ : biological parameters (see their definitions in Table 3 )

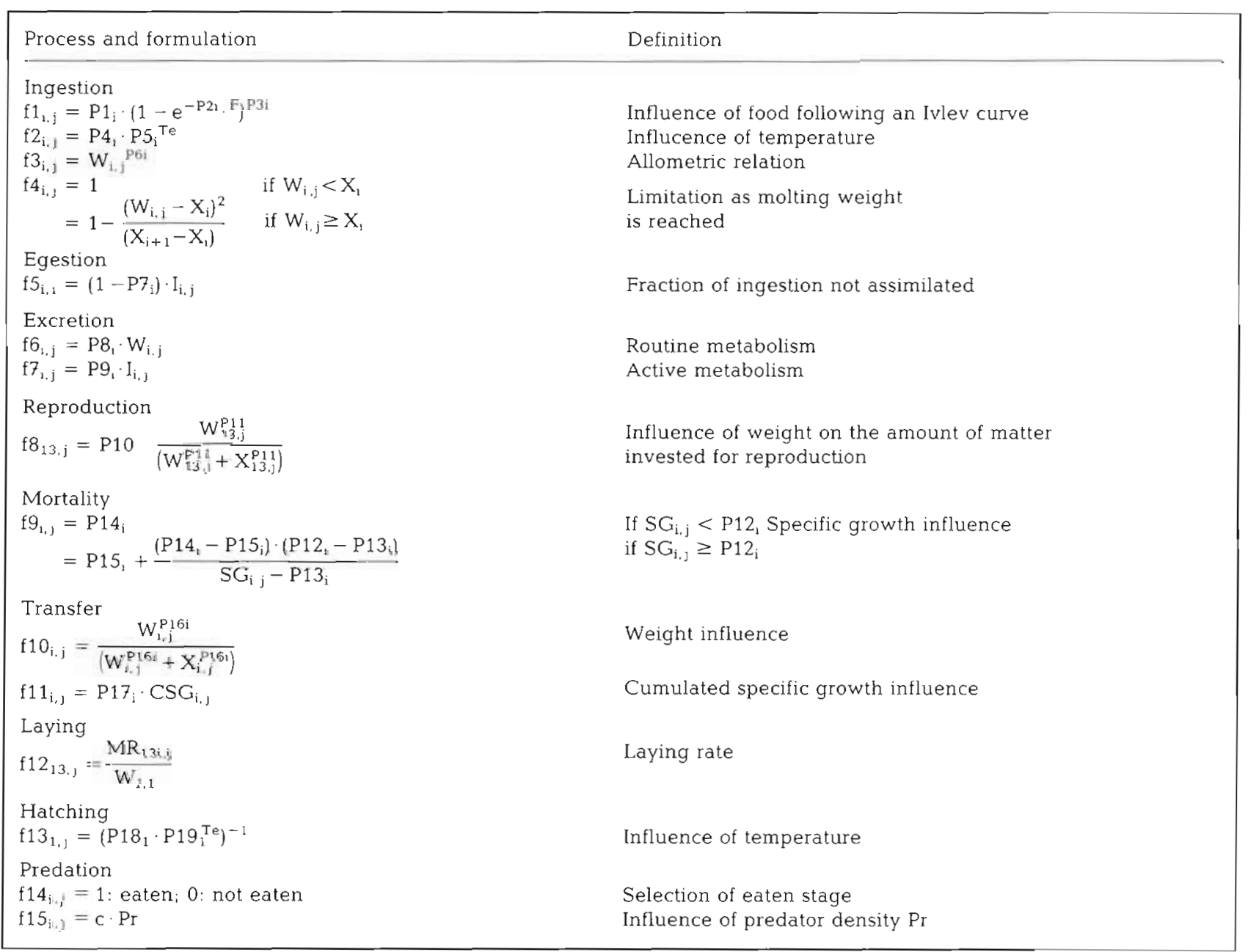

ity rates following their physiological state. So we consider here that mortality rate is a function ( $\mathrm{f} 9$ ) of growth. It is constant and maximal below a threshold value. Above, it decreases following a negative hyperbola whose asymptote represents the minimal rate.

To represent the effects of growth rate and weight on molting rate following the assumptions cited above, we use respectively a linear (f11) and a sigmoidal relationship (f10). Function f10 is a Michaelis' law with exponent (P16), which gives an inflexion point. The value of the exponent influences the slope of the curve around the inflexion point, the abscissa of which is the critical molting weight. These functions allow representation of a continuous increase of the molting probability when the optimal weight and growth are approached.

We assume that all the laid eggs are physiologically equivalent. The hatching rate (f13) is simply formulated as the inverse of the embryonic duration, that is controlled by temperature only.
Predators are forcing variables in this study. Their action is formulated by functions $\mathrm{f} 14$ and $\mathrm{f} 15$ which respectively take into account the instars and the number of predators.

\section{CALIBRATION}

To implement our model, we use experimental results on the dynamics and physiology of Euterpina acutifrons (Bernard 1963, Haq 1965, 1972, 1973, Neunes \& Pongolini 1965, Moreira \& Vernberg 1968, Nassogne 1969, 1970, Vernberg \& Moreira 1974, 1981, Moreira 1975, Zurlini et al. 1978, D'Apolito \& Stancyk 1979, Yassen 1979, Zurlini \& Ferrari 1979, Sciandra 1982. 1968a, Moreira et al. 1985). Most of the coefficients used in the model (Table 3) are calculated from these results. Where data are lacking, coefficients are estimated from knowledge about similar species, in order to optimize the fit of simulations to chronological series. 
Table 2. Processes and system of differential equations. $N_{i, j}$ : abundance

\begin{tabular}{|c|c|c|c|}
\hline Process & Units & Formulation & \\
\hline \multicolumn{4}{|l|}{ Growth } \\
\hline Ingestion (I) & $\mu \mathrm{g}$-at. $\mathrm{N} \mathrm{d}^{-1} \mathrm{i}^{-1}$ & $\mathrm{I}_{\mathrm{i}, \mathrm{j}}=\mathrm{f} 1_{1, j} \cdot \mathrm{f} 2_{\mathrm{i}, \mathrm{j}} \cdot \mathrm{f} 3_{\mathrm{i}, \mathrm{j}} \cdot \mathrm{f} 4_{\mathrm{i}, \mathrm{j}}$ & (1) \\
\hline Egestion (EG) & $\mu \mathrm{g}$-at $\mathrm{N} \mathrm{d}^{-1} \mathrm{i}^{-1}$ & $E G_{i, 1}=f 5_{i, 1}$ & (2) \\
\hline Excretion (EX) & $\mu \mathrm{g}$-at $\mathrm{N} \mathrm{d}^{-1} \mathrm{i}^{-1}$ & $\mathrm{EX}_{\mathrm{i}, 1}=\mathrm{f} 6_{1,1}+\mathrm{f} 7_{1, j}$ & (3) \\
\hline Matter for reproduction (MR) & $\mu g$-at. $\mathrm{N} \mathrm{d}^{-1} \mathrm{i}^{-1}$ & $\mathrm{MR}_{13,1}=f 8_{13, \mathrm{j}}$ & (4) \\
\hline Growth (G) & $\mu \mathrm{g}$-at. $\mathrm{N} \mathrm{d}^{-1} \mathrm{i}^{-1}$ & $G_{i, j}=I_{i, j}-E X_{i, j}-E G_{i, j}$ & (5) \\
\hline Specific growth (SG) & $d^{-1}$ & $\mathrm{SG}_{\mathrm{i}, j}=\frac{\mathrm{G}_{\mathrm{i}, \mathrm{j}}}{\mathrm{W}_{i, 1}}$ & (6) \\
\hline Cumulated specific growth (CSG) & $d^{-1}$ & $\operatorname{CSG}_{\mathrm{i}, j}=\frac{1}{\Delta t} \int_{t-\Delta t} \mathrm{SG}_{\mathrm{i}, j} \mathrm{dt}$ & (7) \\
\hline \multicolumn{4}{|l|}{ Dynamics } \\
\hline Transfer $(\mathrm{T})$ & $d^{-1}$ & $T_{i, j}=f 10_{i, j} \cdot f 11_{i, j}$ & (8) \\
\hline Laying (L) & $d^{-1}$ & $\mathrm{~L}_{13, j}=\mathrm{f} 12_{13, j}$ & (9) \\
\hline Hatching $(\mathrm{H})$ & $d^{-1}$ & $\mathrm{H}_{1,1}=\mathrm{f} 13_{1,1}$ & $(10)$ \\
\hline Mortality (M) & $d^{-1}$ & $M_{i, j}=f 9_{i, j}$ & (11) \\
\hline Predation (P) & $d^{-1}$ & $P_{1, j}=f 14_{i, j} \cdot f 15_{1, j}$ & $(12)$ \\
\hline \multicolumn{4}{|l|}{ Differential equations } \\
\hline \multicolumn{4}{|l|}{ Growth } \\
\hline Eggs $(i=1)$ & & $\frac{d W_{1,1}}{d t}=0$ & $(13)$ \\
\hline N1 to $\mathrm{C} 5(\mathrm{i}=2$ to 12$)$ & & $\frac{d W_{i, j}}{d t}=G_{i, j}$ & (14) \\
\hline Adults $(i=13)$ & & $\frac{W_{13, j}}{d t}=G_{13, j}-M R_{13, j}$ & (15) \\
\hline \multicolumn{4}{|l|}{ Dynamics } \\
\hline Eggs $(i=1)$ & & $\frac{d N_{1 ; 1}}{d t}=L_{13, j} \cdot N_{13, j}-\left(H_{1,1}+M_{1,1}+P_{1,1}\right) \cdot N_{1,1}$ & $(16)$ \\
\hline N1 (1st age class) & & $\frac{d N_{2,1}}{d t}=H_{1,1} N_{1,1}-\left(T_{2,1}+M_{2,1}+P_{2,1}\right) \cdot N_{2,1}$ & (17) \\
\hline N2 to C5 (1st age class) & & $\frac{d N_{1 ; 1}}{d t}=\sum_{i=1}^{n} T_{1}-{ }_{1 ; j} \cdot N_{i-1, j}-\left(T_{l, 1}+M_{i, 1}+P_{1,1}\right) \cdot N_{1,1}$ & (18) \\
\hline N1 to C5 (next age class) & & $\frac{d N_{i, j}}{d t}=-\left(T_{i, j}+M_{i, j}+P_{i, j}\right) \cdot N_{i, j}$ & (19) \\
\hline Adults (1st age class) & & $\frac{\mathrm{N}_{13,1}}{\mathrm{dt}}=\sum_{1=1}^{\mathrm{n}} \mathrm{T}_{12 ; 1} \cdot \mathrm{N}_{12, j}-\left(\mathrm{M}_{13,1}+\mathrm{P}_{13,1}\right) \cdot \mathrm{N}_{13,1}$ & $(20)$ \\
\hline Adults (next age classes) & & $\frac{d N_{13 i j}}{d t}=-\left(M_{13, j}+P_{13, j}\right) \cdot N_{13, j}$ & $(21)$ \\
\hline
\end{tabular}

\section{Coefficients of growth and egg-laying processes}

In the Ligurian Sea, Euterpina acutifrons lives at temperatures between 10 and $25^{\circ} \mathrm{C}$. All the relations used in this model are valid within this scale of variation.

The values of ingestion, egestion and excretion coefficients (P1 to P10) were found in the literature for copepodid and adult stages. Very little information is available for naupliar stages of Euterpina acutifrons. We assume that the coefficients for naupliar stages can be approximated by extrapolating from the relationships demonstrated for copepodids and adults.

The values (P1, P2 and P3) of Ivlev curve f1 for adults fed with the diatom Phaeodactylum tricornutum at $20^{\circ} \mathrm{C}$ were obtained from Sciandra (1982) for adults. According to the review by Kremer \& Nixon (1978) on Acartia clausi, the maximal ingestion rate increases exponentially with temperature following a $Q_{10}$ varying from 1.6 to 3.3 . We use an intermediate value of 2.6 to estimate the P5 coefficient. Coefficient P4 is calculated so that $\mathrm{f} 2$ is equal to 1 at $20^{\circ} \mathrm{C}$. Fernandez (1979) observed that the ingestion rate per individual increases during the development of Calanus pacificus. For N1 to C3 instars, we have extrapolated the coefficient P1 considering a similar increase. Coefficients P2 to P5 are identical for all stages. The exponent P6 of the allometric relation between weight and ingestion generally lies between 0.6 and 0.8 for copepods (Suschenya 1970, Paffenhöfer 1971). Because of the ab- 


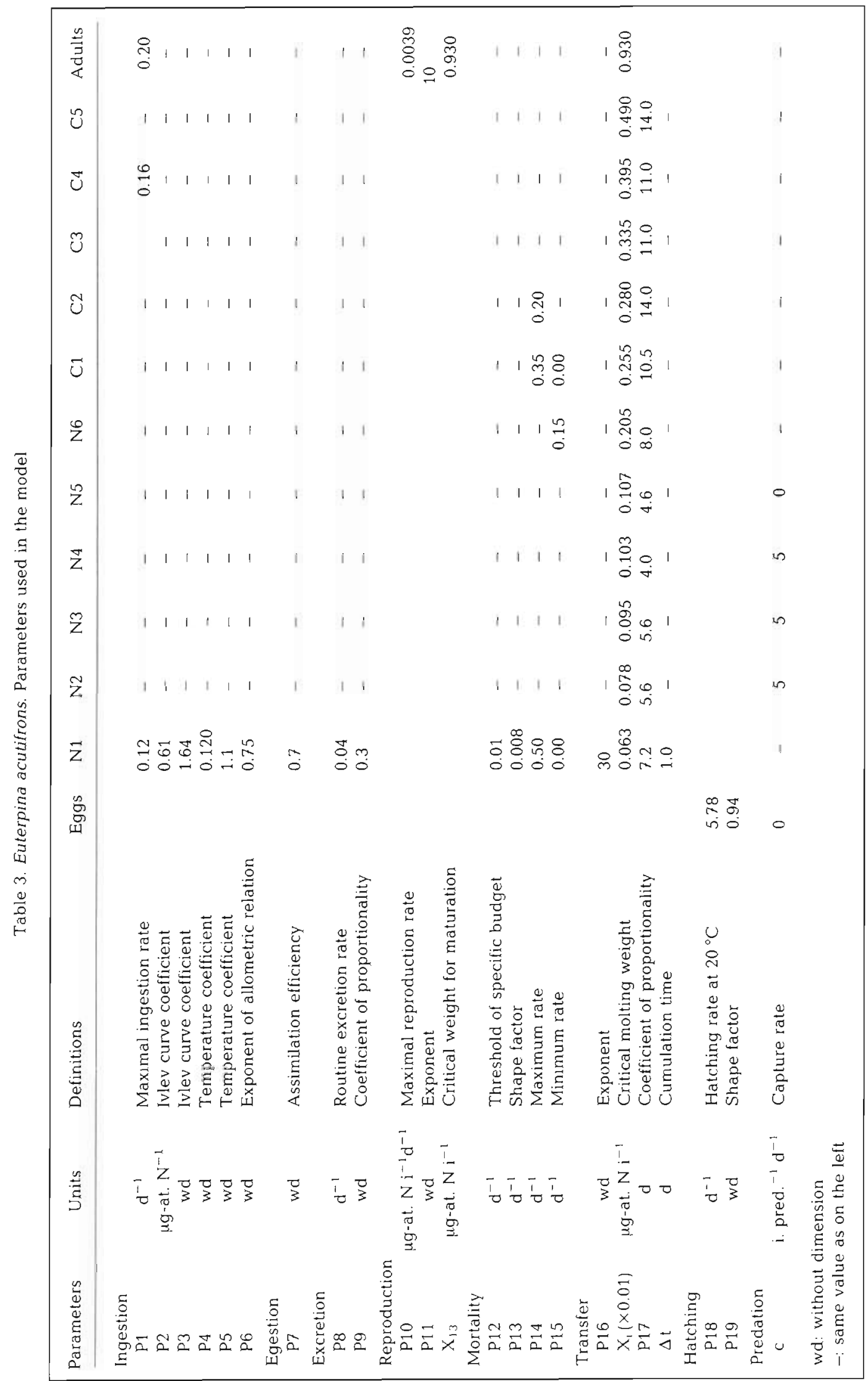




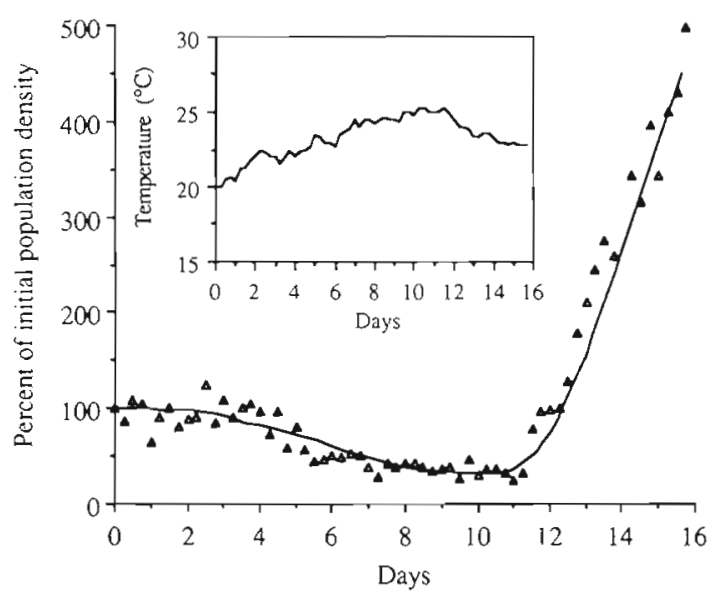

Fig. 2. Euterpina acutifrons. Total population during development, with variable temperature and constant food supply. $(\Delta)$ Experimental data from Sciandra (1986a); (-) simulation. The simulation starts with Nauplii 1 having identical weights $\left(0.5 \times 10^{-3} \mu\right.$ g-at. $N$ ind. $\left.{ }^{-1}\right)$ and ages

sence of data for Euterpina acutifrons, we adopt a value of 0.75 for all the instars.

An average value of 0.7 is generally considered as representative of the assimilation rate (P7) of copepods (Conover 1966, Steele 1974).

Supposing first that $30 \%(\mathrm{P9})$ of the ingested matter is used for metabolism and is excreted, and second, that the ratio of maximum ingestion rate to weight averages $20 \%$ (Sciandra 1982), a daily excretion rate of $6 \%$ of weight may be attributed to the active metabolism. To adjust total metabolic losses to an average value of $10 \%$ of weight per day (Corkett \& McLaren 1978, Miller \& Landry 1984), we estimate that excretory wastes due to minimal metabolism (P8) represent $4 \%$ of the body weight.

We assume a sex ratio of 0.5. Yassen (1979) estimated egg weight to $3 \times 10^{-4} \mu \mathrm{g}$-at. $\mathrm{N}$. Considering an optimal egg-laying rate ranging from 10 to 13 eggs female ${ }^{-1}$ $\mathrm{d}^{-1}$ (Zurlini et al. 1978, Sciandra 1986a), the maximal amount of matter that can be invested daily per female for reproduction (P10) approaches $39 \times 10^{-4} \mu \mathrm{g}$-at. $\mathrm{N}$.

\section{Coefficients of developmental processes}

The coefficients of the relationships between growth and development are unknown, because of the theoretical nature of the assumptions put forward. So they have been determined by fitting simulations to chronological series of data. We have used a set of data obtained by Sciandra (1986a) on the development of Euterpina acutifrons at variable temperature with constant food supply (16 $\mu$ g-at. $\left.\mathrm{N}^{-1}\right)$. Mortality rate coefficients (P12, P13, P14, and P15) have been estimated using the total population (Fig. 2) and the stage curves (Fig. 3), i.e. 13 chronological series. Densities of N6 are lower than those of $\mathrm{N} 5$ and $\mathrm{C} 1$, so that a higher death rate has been attributed to stage N6. With a simple model, Sciandra (1986a) came to the same conclusion. $\mathrm{He}$ also pointed out that instars N5 and N6 are very difficult to distinguish, suggesting that some confusion may exist between these stages. It has also been shown that molting from instar N6 to $\mathrm{C} 1$ may be a critical period of development (Paffenhöfer 1970, Haq 1972, D'Apolito \& Stancyk 1979).

Molting rate coefficients $\left(\mathrm{X}_{1}, \mathrm{P} 16\right.$ and P17) were estimated successively for each stage curve. The critical weight of molting $\left(X_{1}\right)$ for each instar $i$ and the critical weight of laying $\left(\mathrm{X}_{13}\right)$ influence the position of the beginning of the stage curves (see the sensitivity analysis in Nival et al. 1988). The exponent P16 and the coefficient of proportionality P17 respectively influence the initial slope and the end of the curve. The part of the total variance in abundance explained by the model in the 2 fits (Figs. 2 and 3) are respectively equal to 0.98 and 0.92 .

\section{SIMULATIONS AND APPLICATIONS}

The system of differential equations is solved by fourth-order Runge-Kutta numerical integration with a time step of 1 h. Simulations presented in Figs. 2 and 3 reproduce satisfactorily the principal aspects of the

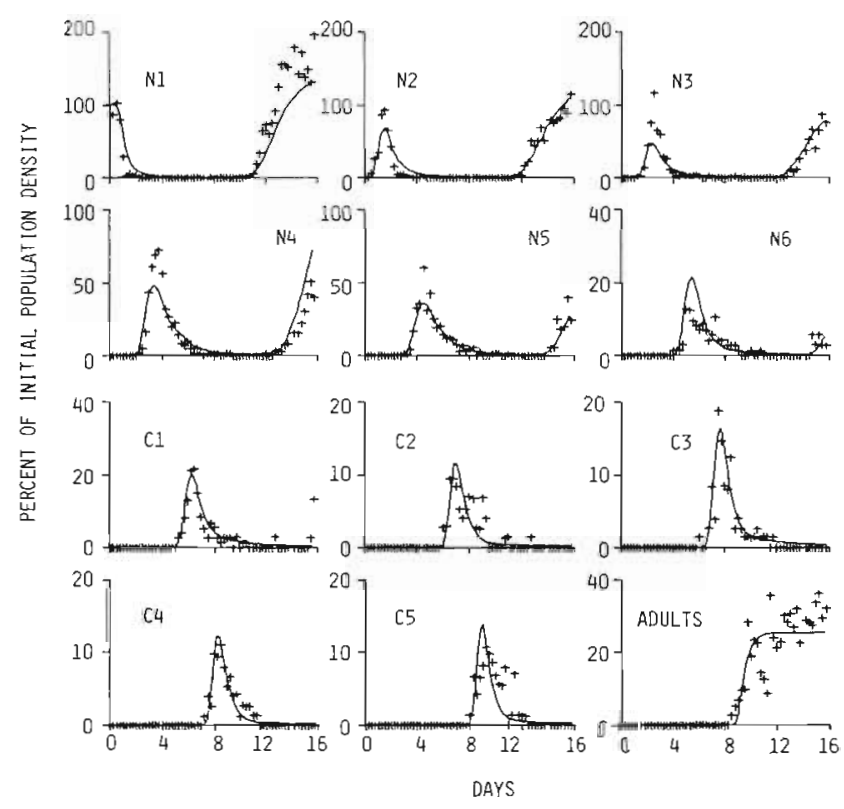

Fig. 3. Euterpina acutifrons. Stages (6 nauplii, 5 copepodites and adults) during development. (+) Experimental data from Sciandra (1986a); (-) simulations. See Fig. 2 for initial conditions and forcing variables 


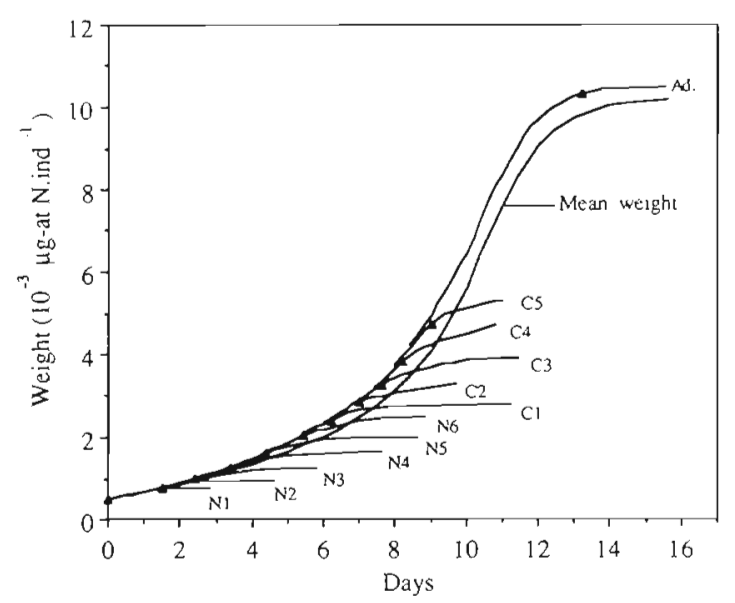

Fig. 4. Euterpina acutifrons. Simulated time courses of stage weights during total development. Curves are stopped when stage sizes represent less than $0.5 \%$ of the total population. The curve of mean weight is obtained by averaging weights of all individuals. ( $\wedge$ ) Weights of individuals at their maximum stage

dynamics: timing of appearance and disappearance of copepods in their developmental stages, and time of generation. In particular, the asymmetry of stage distributions is well represented, which was not possible with the model of Sciandra (1986a). Nevertheless, some discrepancies appear for the maximal amplitude of the early stages. The second generation is well represented suggesting a good representation of the egg-laying process.

\section{Individual and population growth}

The model allows us to present 3 sets of results (Fig. 4): (1) the mean weight of the whole population; (2) the weight of individuals at their maximal abundance in successive stages; (3) the mean weight of individuals in each instar. These results are obtained from the simulations presented in Fig. 3. The curve of the population mean weight is sigmoidal suggesting more or less exponential growth in the nauplius and copepodid stages, followed by saturation as adults appear. Similar curves have previously been obtained in the laboratory for Pseudocalanus elongatus (Paffenhöfer \& Harris 1976). Temora longicornis (Harris \& Paffenhöfer 1976), Acartia clausi and A. tonsa (Miller et al. 1977), Calanus pacificus and Pseudocalanus sp. (Vidal 1980a), Calanus finmarchicus (Corner et al. 1967. McLaren 1986). Eudiaptomus graciloides (Hamburger \& Boëtius 1987). Fig. 4 shows that growth is maximal between copepodid V and adult stages. Some copepod species such as Temora longicornis (Harris \& Paffenhöfer 1976, Razouls \& Razouls 1976) have the same pattern of growth.
Fig. 4 shows that the mean weight of an individual during its complete development cannot be correctly estimated by simply weighing copepods at their maximal abundance in successive stages. The overestimation due to this method in comparison with the true estimation (mean curve) increases as new stages appear. This is explained by the fact that stages overlap more and more as development completes, leading the population to be less homogeneous in its stage composition. By taking into account only individuals at maximum stages, individuals lighter in weight which remain in previous stages are neglected. Fig. 4 also shows that the mean growth, which seems to be continuous on the overall development, is in fact the sum of the discontinuous growths of successive stages. For each of them, weight cannot exceed a given value, so that copepods continue to grow only if they succeed in molting into the next instar.

Simulated weights are in good agreement with the weight of Euterpina acutifrons measured by Zurlini et al. (1978), Yassen (1979) and Moreira et al. (1985) (Table 4). The marked difference between C5 and female weights reproduced by the model can also be observed for other harpacticoids (Herman \& Heip 1985).

Fig. 5 clearly demonstrates that the time variation of the total population biomass results from the combination of dynamics (Fig. 2) and growth processes (Fig. 4). Until Day 5, population biomass increases because individual weight gain compensates mortality. Total biomass decreases during the time where N6 and C1 stages are preponderant in the population, because of their higher mortality rate. Between Days 10 and 13 the rapid weight increase is primarily due to adult growth. It is also clear that copepods which remain late in each stage may constitute an important proportion of total population weight, which explains the discrepancy cited above.

\section{Influence of temperature}

The model was used to simulate the effect of temperature on the development of Euterpina acutifrons between 10 and $25^{\circ} \mathrm{C}$. Fig. 6 shows that with nonlimiting food, naupliar and total development times expressed on a log scale (Fig. 6) decrease approximately linearly as temperature increases, suggesting a constant $Q_{10}$ between 10 and $25{ }^{\circ} \mathrm{C}$. The experimental results on the same species given by Bernard (1963, his Table 3), Haq (1972, his Fig. 1) and D'Apolito \& Stancyk (1979, their Table 5) are in good agreement with the present simulations (Table 5). $Q_{10}$ calculated between 10 and $20^{\circ} \mathrm{C}$ for naupliar and total development is respectively 3.52 and 3.44 , of the same order as $\mathrm{Q}_{10}$ measured by Haq (1972) (respectively 4.20 and 
Table 4. Euterpina acutifrons. Instar mean weights $\left(10^{-3}\right.$ $\mu \mathrm{g}$-at. $\mathrm{N}$ ind. ${ }^{-1}$ ) obtained by the model and from the literature after conversion from dry weight into nitrogen content. Values of Yassen (1979) were obtained from mean weights of several stages in the same culture

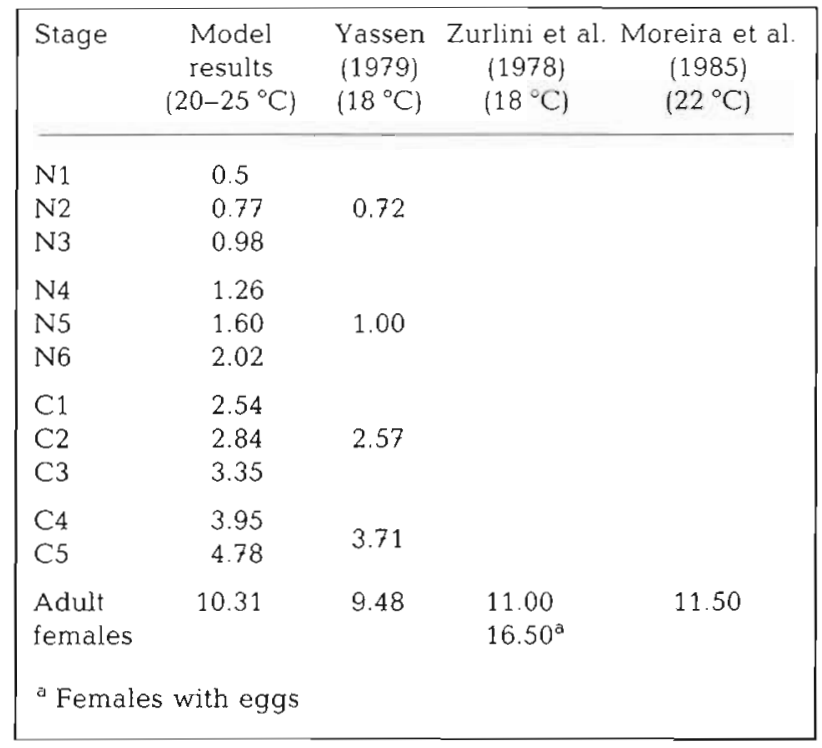

4.10). It is higher than the $\mathrm{Q}_{10}$ adopted for ingestion (2.6). The calculated stage durations at $18{ }^{\circ} \mathrm{C}$ are consistent with the results of Neunes \& Pongolini (1965) obtained with $E$. acutifrons in culture.

Although our representation of the temperature effect is very simple, the model is able to reproduce the most important features of its action on the development rate. Generally, temperature is hypothesized to influence several processes involved in the metabolism such as filtration, ingestion, excretion, or more global processes such as growth or development. Our results show that the effect of temperature on ingestion only, which has an indirect effect on excretion and assimilation, is sufficient to simulate correctly the action of temperature on the development rate. This is not sur-

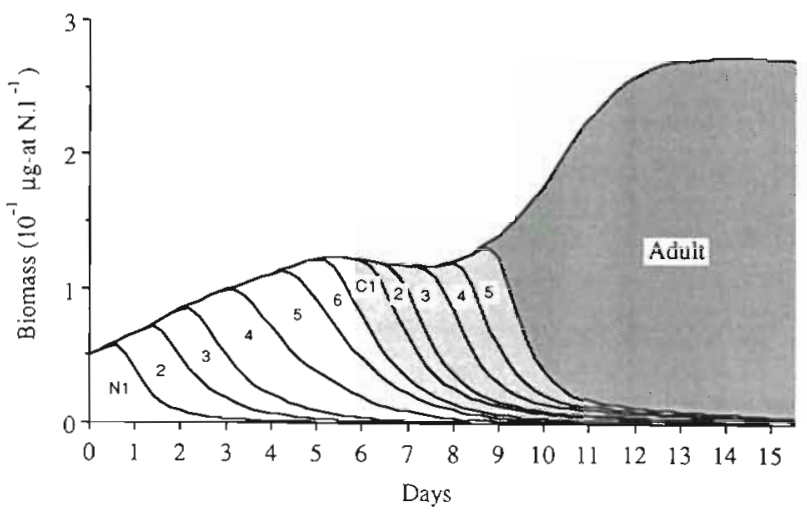

Fig. 5. Euterpina acutifrons. Simulated distribution of biomass among stages during total development. Upper limit represents total biomass of the population

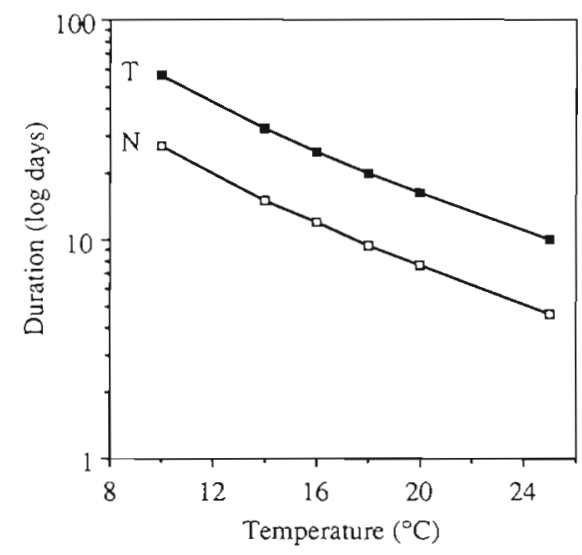

Fig. 6. Euterpina acutifrons. Simulated durations of naupliar $(\mathrm{N} ; \square)$ and total $(\mathrm{T} ; \boldsymbol{m})$ development under different temperature and non-limiting food conditions

prising since we have considered first that the active metabolism was only related to the ingestion activity, and second that excretion rate was a function of the ingestion rate. By linking temperature and ingestion process, any variation of this external factor has repercussions on metabolic rate through the processes of assimilation and excretion.

Fig. 7 has been constructed using the same simulations as in Fig. 6. Stage weights and the corresponding time reported in this figure are calculated at the maximal abundance in each stage. For different temperatures, growth approaches an exponential form. Miller et al. (1977, his Fig. 7) obtained similar results

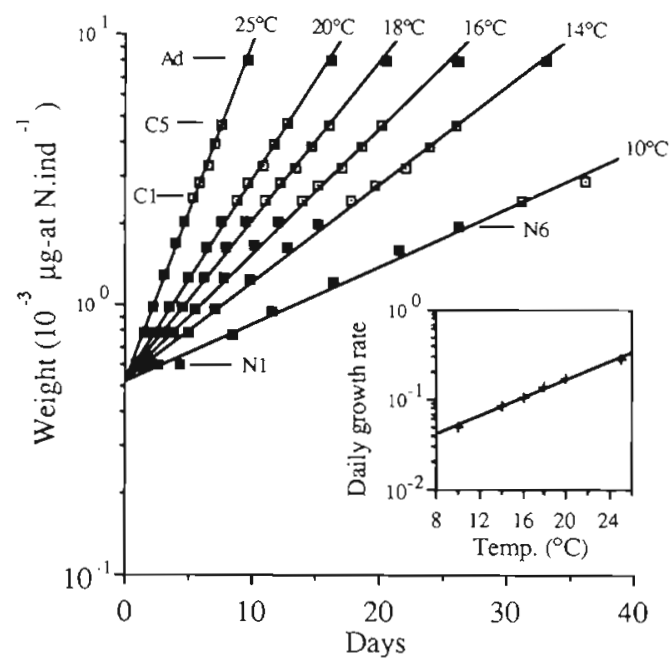

Fig. 7. Euterpina acutifrons. Simulated time-courses of stage weights during development at different temperatures, and with non-limiting food. Growth rates are estimated from exponential adjustments, and are reported for the different temperatures. $A Q_{10}$ of 3.47 is evaluated in the range of temperature studied. Reported adult weights are those calculated at the beginning of egg-laying 


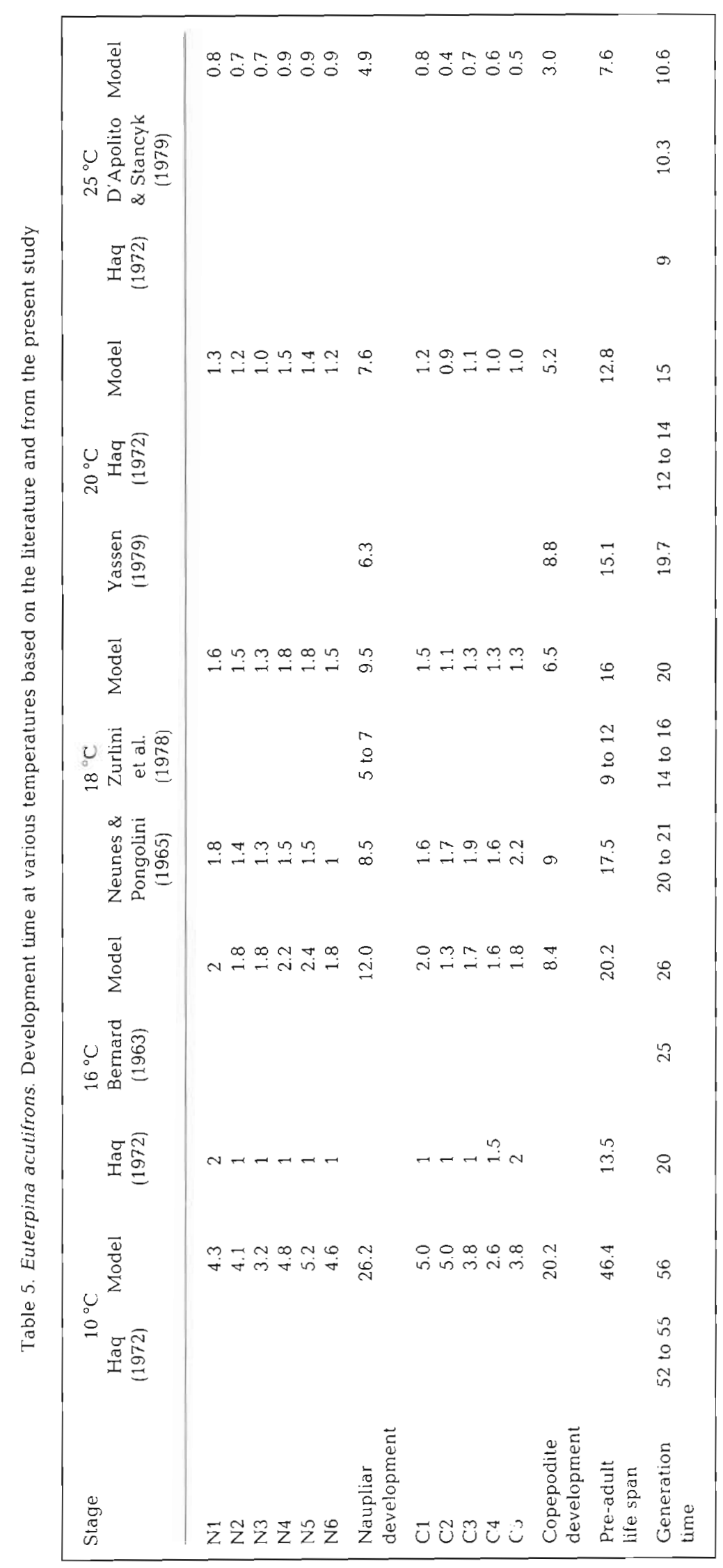


with experiments on Acartia tonsa. The present Fig. 7 suggests that the development of Euterpina acutifrons is equiproportional (sensu McLaren 1986), since temperature variation does not modify the ratio between the different stage lengths.

\section{Influence of food concentration}

The ability of the model to simulate the influence of different food concentrations was tested by comparing simulations with 2 sets of data obtained by Sciandra (1986a). Development was only followed in the first 4 naupliar stages at constant temperature $\left(22^{\circ} \mathrm{C}\right)$ and for 2 concentrations of the diatom Phaeodactylum tricornutum: 2 and $13 \mu \mathrm{g}$-at. $\mathrm{N}^{-1}$ (Fig. 8A, B). Model coefficients remain unchanged.

Fits are good for the high food series. Timing of development stages and amplitude of maximal abundance are well reproduced by the model. For the low food series, adjustments are acceptable for stages N1 and N2 for which simulated curves have the same asymmetry as in experimental results. For stages N3, the initial slope is well represented, but the terminal part of the curve is too low. Nevertheless, the model is able to simulate 2 important properties at low food level: first the lower speed of development (stage peaks occur later in Fig. 8B than in Fig. 8A); second the greater proportion of individuals which stay a longer time in the stages.

Low food conditions seem to have another effect which was discussed by Sciandra (1986a), and cannot be accomodated in a deterministic model. Variability in Fig. 8B is much greater than in Fig. 8A. The part of the total variance explained by the model is respectively 0.94 and 0.84 for the high and low food conditions. Our model, which only explains the deterministic properties of individuals, is unable to account for the effect of variability on the population development. This can be seen from the increasing discrepancy between simulations and experiments for the N3 and N4 stages. Limitations of deterministic representations have to be kept in mind to clearly identify what part of the population properties may be attributable to individual properties.

Fig. 9 gives a synthetic representation of the influence of food concentration on the duration of the naupliar and total development, simulated at a constant temperature of $22^{\circ} \mathrm{C}$. For concentrations higher than about $4 \mu \mathrm{g}$-at. $\mathrm{N}^{-1}$, there is no marked influence because of the saturation of the ingestion process formulated by the Ivlev relationship. Between 1 and $3 \mu \mathrm{g}-$ at. $\mathrm{N}^{-1}$, development is strongly affected by the variation of food level. For concentrations lower than $0.5 \mu \mathrm{g}$ at. $\mathrm{N} \mathrm{I}^{-1}$, copepods die before reaching their total development. Similar results have been obtained
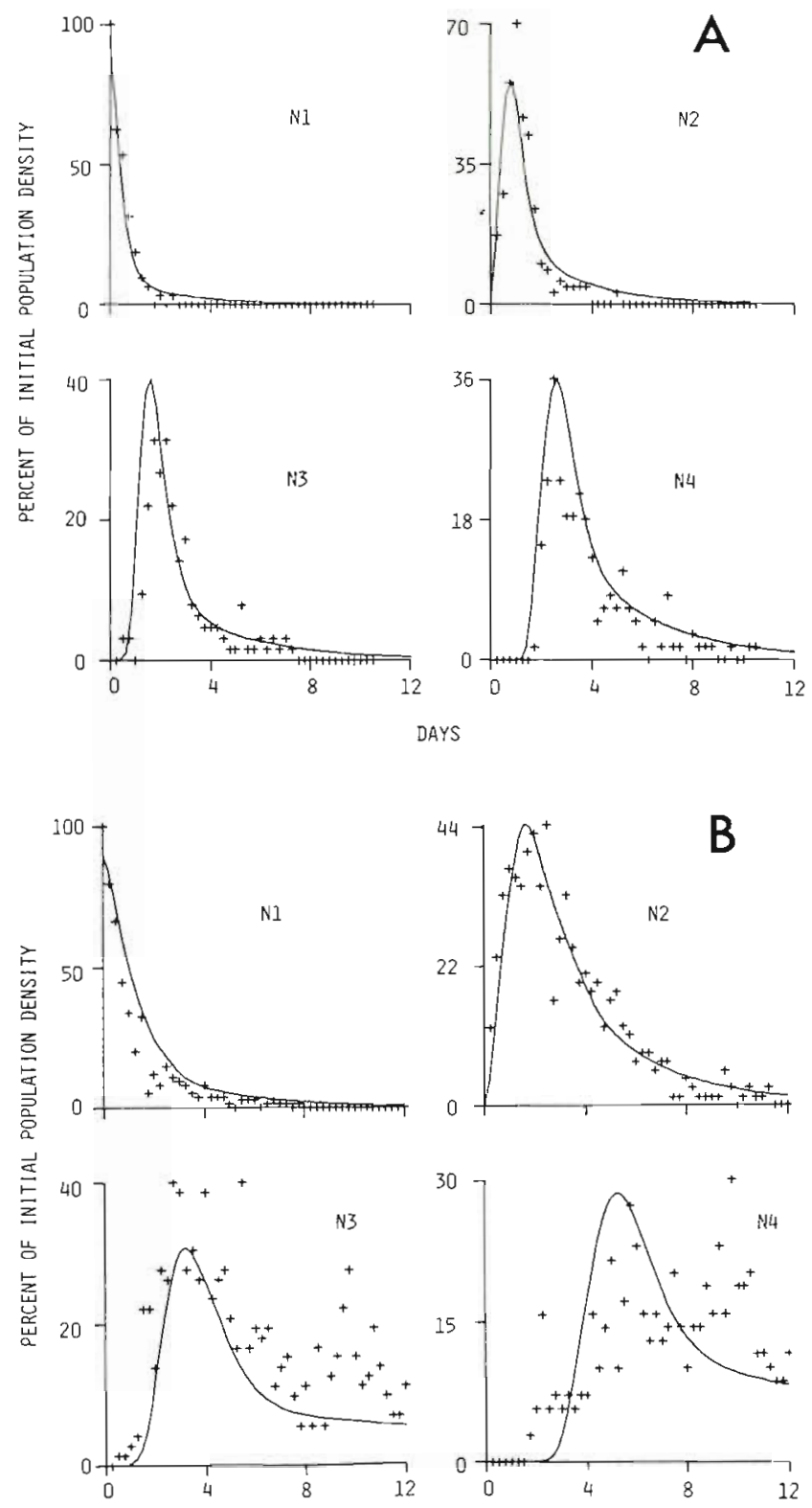

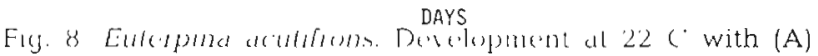
non-limiting and $(B)$ limiting food concentrations. ( + ) Data from Sciandra (1986a); (-) simulations. Simulations start with 90 Nauplii 1,10 weighing $0.4 \mu \mathrm{g}$-at. $\mathrm{N}, 20$ weighing 0.5 $\mu \mathrm{g}$-at. $\mathrm{N}$, and 60 weighing $0.6 \mu \mathrm{g}$-at. $\mathrm{N}$, to take into account

that the laying period lasts for $16 \mathrm{~h}$ (see Sciandra 1986a)

experimentally on Calanus helgolandicus (Paffenhöfer 1970, 1971), Calanus pacificus (Vidal 1980b), and a cladoceran species, Eudiaptomus graciloides (Weglenska 1971).

Fig. 10 is based on the same simulations and shows that growth is fairly exponential for high as well as for low food levels. Growth rates are reduced especially for concentrations lower than $3 \mu \mathrm{g}$-at. $\mathrm{N} \mathrm{I}^{-1}$. Experiments by Berggreen et al. (1988, their Figs. 4 and 5) show that 


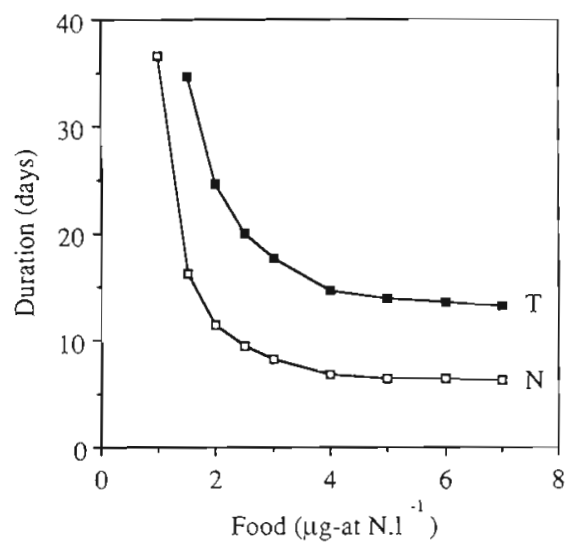

Fig. 9. Euterpina acutifrons. Simulated durations of naupliar $(\mathrm{N} ; \square)$ and total $\left(\mathrm{T}_{i} \boldsymbol{)}\right)$ development at $22^{\circ} \mathrm{C}$ with different food concentrations

growth of Acartia tonsa is exponential and constant throughout development at all food concentrations, although Miller et al. (1977) observed the contrary for the same species at very low food concentrations. Our results are also in good agreement with experiments of Harris \& Paffenhöfer (1976) on Temora longicornis, Hamburger \& Boëtius (1987) on Eudiaptomus graciloides, and Tessier \& Goulden (1987) on Daphnia magna.

The model allows us to calculate simultaneously the time courses of metabolic (Fig. 11A) and molting rates from N2 to N3 stage (Fig. 11B). Molting rate curves have the classical shape reported by Sulkin \& Van Heukelem (1986). The asymmetry due to the terminal part of the curves was experimentally observed by Miller et al. (1984). The period during which molting

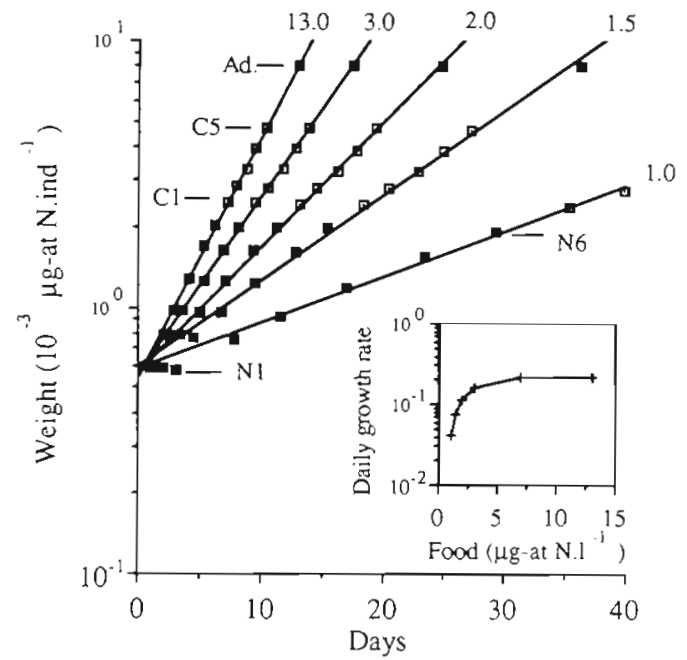

Fig. 10. Euterpina acutifrons. Simulated time courses of stage weights during development at $22^{\circ} \mathrm{C}$, with different food concentrations $\left(1,1.5,2,3\right.$, and $13 \mu \mathrm{g}$-at. $\left.\mathrm{Nl}^{-1}\right)$. Growth rates are estimated from exponential adjustments, and are reported at the different food levels. Reported adult weights are those calculated at the beginning of egg-laying
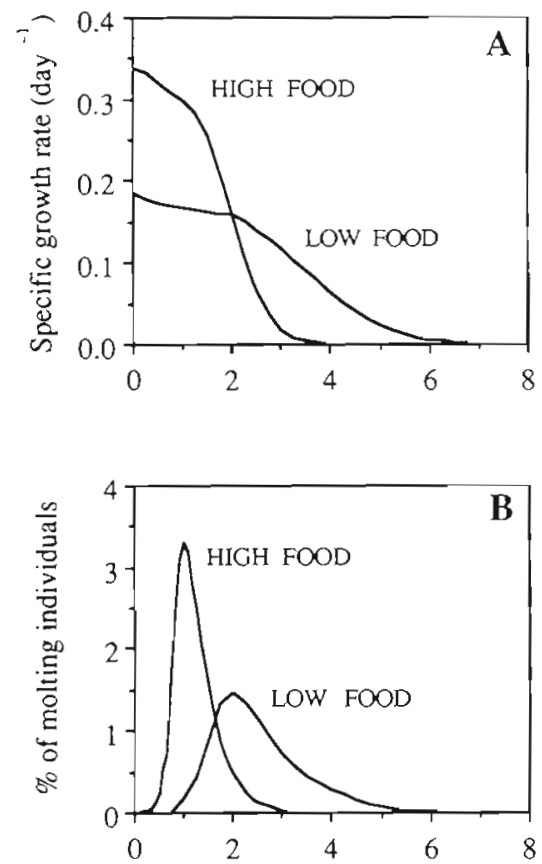

Fig. 11. Euterpina acutifrons. Simulated time courses of (A) the specific budget and (B) transfer rate for individuals molting from stage $\mathrm{N} 2$ to stage $\mathrm{N} 3$, with limiting and non-limiting food concentrations. The $\%$ of molting individuals is calculated from the ratio of the number of copepods passing into stage N3 per day to the number of individuals remaining in stage N2. Time 0 corresponds to the time when N2 stage starts increasing

occurs is longer for low food level, but the maximal rate of molting is higher for high food level. The explanation is given by the specific growth rate curves. For the high food level, specific growth rate is optimal so that weight of Nauplii 2 increases rapidly, leading the molting rate to become maximal in a short time, according to the relationships $\mathrm{f} 10$ and $\mathrm{f} 11$. As weight reaches the maximum value possible in stage N2, specific growth rate tends to zero because ingestion activity diminishes according to the relationship 4 . Consequently, molting rate decreases following the relationship f11. Individuals which have not molted although having reached their critical weight are represented by the tail of the simulated distribution. At this time, the peak on Fig. $11 \mathrm{~B}$ corresponds to the slope discontinuity on Fig. 11A.

For low food level, the specific growth rate is lower, leading to slower development of weight and molting rate. Clearly, the shape given to the relationships between the molting rate and both the weight and growth rate strongly influences the shape of the specific growth and transfer curves.

The model is also able to calculate the weight distributions of stages. Such distributions for successive instars clearly show that the use of critical molting weights in the model does not imply that all the individuals molt at these weights (Fig. 12). At the stage 
HIGH FOOD

LOW FOOD

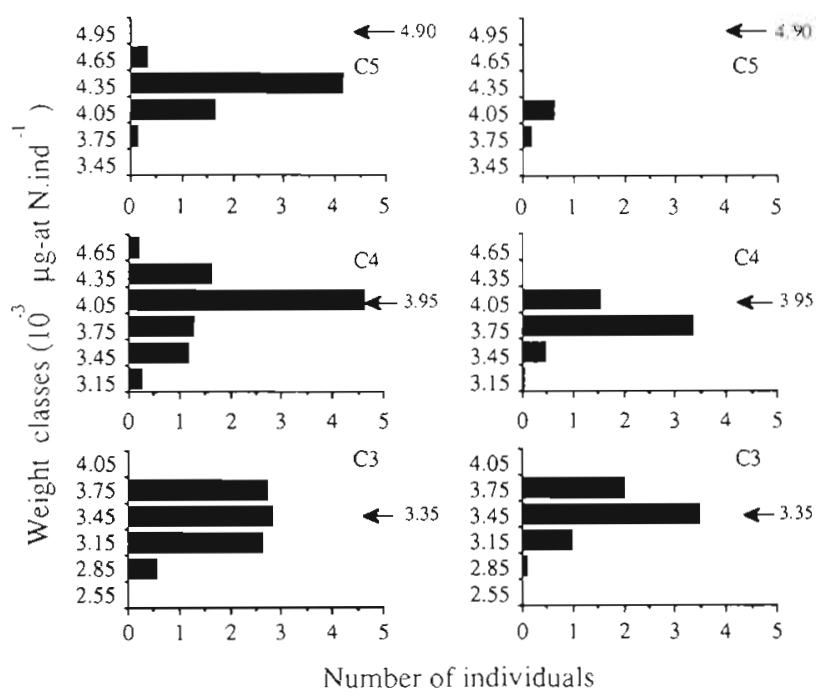

Fig. 12. Euterpina acutitrons. Weight distributions of copepodite instars 3,4 and 5 , at the moment of $\mathrm{C} 4$ peak with limiting and non-limiting food concentrations. Ordinates give the mean value of weight classes. Arrows denote the critical molting weights towards the next instar

peak (C4 in Fig. 12), the weight distribution is shifted towards higher values when the food concentration increases. This is the reason why the mean weights increase when growth rate increases (cf. Figs. 7 and 10).

\section{Applications}

The model can be used to test the effect of variation of forcing variables such as food and predators, which are complex in time and space and may act simultaneously on populations. If only the overall population is considered, their effects on the dynamics are unpredictable since they can occur at different periods of the development, characterized by different stage compositions (Nival et al. 1988). Fig. 13 shows the effects of different patterns of food deprivation and predator occurrence, simulated by the model. In the reference situation (A.1), the decrease of total population is only due to natural mortality which is more important during the N6 to $\mathrm{C} 1$ transition period. If a starvation period occurs, development time and recruitment (\% of initial individuals becoming adults) are changed. Recruitment is more affected when starvation occurs during the naupliar (A2) than during copepodid development (A3), because of the higher mortality rates of stages $\mathrm{N} 6$ and $\mathrm{C} 1$. Absence of food increases the duration of affected stages. According to the selectivity of predators and the time of their occurrence, recruitment may be more or less changed. If predator action and starvation period coincide (B2), effects may be much more dramatic than if they do not (B3).

\section{Basic hypotheses of coupling between growth and dynamics}

The model allows us to test hypotheses on the connections between growth rate and development. The connections were formulated theoretically, because of the lack of knowledge on the relations between molting and growth. Good fits between experimental and simulated data are encouraging. It has to be noted that

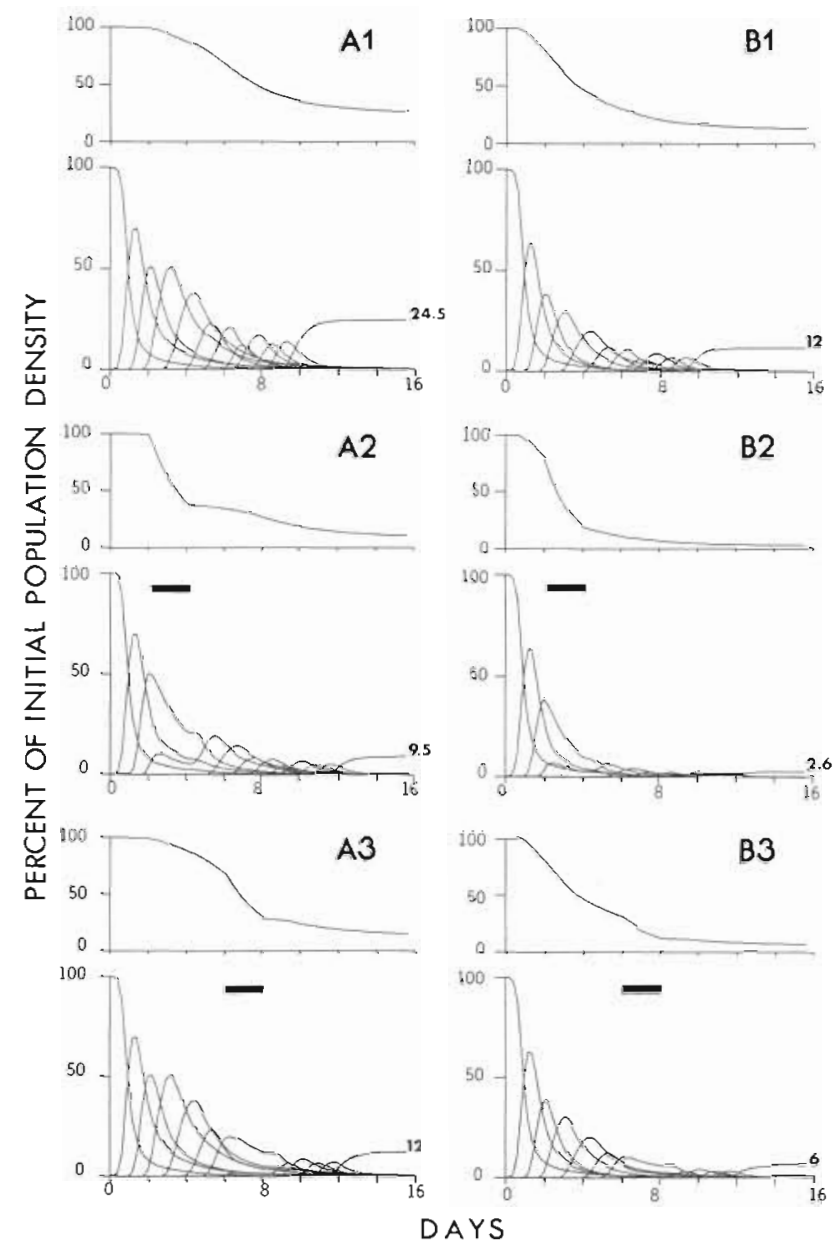

Fig. 13. Euterpina acutifrons. Combined effects of predation and food deprivation on the development and recruitment (taken here as the \% of initial population becoming mature at Day 16, and represented by the number on each graph). Stages and total population time courses (upper graphs) are simulated. A1 is the reference simulation without predator or food deprivation. In A2 and A3, 2 d of total food starvation (symbolized by black bars) begin respectively at Days 2 and 6 . In simulations B1, B2 and B3, food conditions are the same as in $\mathrm{A} 1, \mathrm{~A} 2$ and $\mathrm{A} 3$, but stages $\mathrm{N} 2, \mathrm{~N} 3$ and N4 are assumed to be eaten by predators 


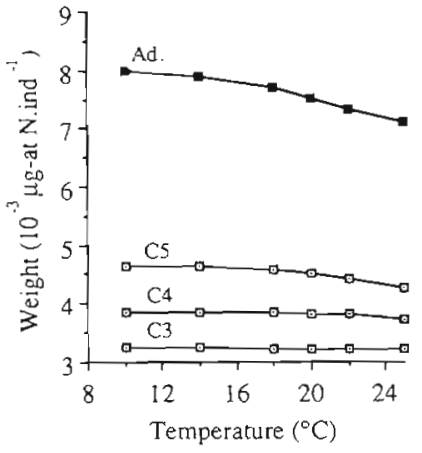

Fig. 14. Euterpina acutifrons. Simulated weight of older instars at different temperatures when their critical molting weights $X_{i}(T)$ are functions of temperature following a Belheradek relationship: $X_{i}(T)=\left(a \cdot i^{b}\right)\left(1-c \cdot[T-d]^{e}\right)$; coefficients a and $b$ relate weight increment per ${ }^{\circ} \mathrm{C}$ with instar i (cf. Corkett \& McLaren 1978, Fig. 27); C, d and e are positive constants. Reported adult weights are those calculated at the beginning of egg-laying. Copepodite weights are taken at their maximal stage abundance

the same model with a unique set of parameters is able to reproduce several sets of data for different food and temperature conditions, suggesting that connections between the different processes are acceptable.

Nevertheless, fits do not prove totally the validity of the representation. Other experiments on dynamics, as well as on biological processes, are necessary to retain or to reject some of the present hypotheses. Especially, it will be necessary to verify experimentally for Euterpina acutifrons that molting occurs more or less at fixed weights, at least in a certain range of variation, since this assumption is of prime importance in the model.

It has been demonstrated for small species that temperature is negatively correlated with weight, especially for the last instar (McLaren 1963, Landry 1975, 1978, Miller et al. 1977, Corkett \& McLaren 1978, Durbin \& Durbin 1978, Vidal 1980a, Durbin et al. 1983). Heinle (1969) and Corkett \& McLaren (1978) showed that body size is not affected below a given temperature, but decreases as temperature exceeds this given value. McLaren (1963) showed that the final size of adults depends on the mean temperature during the whole lifetime (cf. his Fig. 3). By considering firstly that the critical weight of molting is constant, and secondly that temperature influences only ingestion and excretion rate, the model cannot reproduce the relation between temperature and weight. This means that long-term effects of temperature should be represented by a process taking into account a different and supplementary physiological process. Miller et al. (1977) suggested the influence of an hormonal control leading to uncoupled growth and development. Although hormonal metabolism of crustaceans seems complex (Skinner 1985a, b), molting occurs when a certain hor- mone exceeds a threshold (Anger 1987. Anger \& Spindler 1987).

We modified our model by adding an empirical relationship in which the critical molting weights of the oldest instars decrease when temperature exceed a given value. Simulations obtained at different temperatures (as for Fig. 7) reproduce this effect (Fig. 14), but the important fact is that the development is not affected. Development times in the different instars remain nearly unchanged. The part of the total variance in abundance explained by the modified model is equal to 0.96 and 0.91 respectively for the experimental data of Figs. 2 and 3, whereas it was 0.98 and 0.92 for the initial model.

\section{DISCUSSION}

There is a hierarchy between processes in that both food and temperature act on ingestion which, in turn, influences the rate of excretion, so that excretion rate is not directly influenced either by temperature or by food (Fig. 1). This assumption results logically from the fact that excretion is a physiological process induced by other metabolic activities. Since the routine metabolism has been supposed to be independent of the temperature, the $Q_{10}$ law used for the ingestion process applies directly to the whole metabolic rate. This assumption holds for animals whose different enzymatic activities are similarly influenced by variations of temperature.

The $Q_{10}$ for growth is equal to 3.47 and is in the same range as those calculated for naupliar (3.44) and total developments (3.52). The model allows us to state that fixed molting weights and uniform $Q_{10}$ for growth are 2 conditions leading to a constant $Q_{10}$ for development (Fig. 6).

Following our representation, growth is exponential, even at very low food concentration (Fig. 10). This is because firstly, fixed molting weights have been considered, and secondly, the coefficients of processes which control the metabolic rate are similar for each stage. It is clear from the model, which assumes that both growth and weight control the molting process, that food as well as temperature limit development. However, the effect of food is limited to low concentrations (Figs, 9 and 10) because of the Ivlev relationship used for the ingestion. The saturation observed in growth rate in Fig. 10 and the form of curves in Fig. 9 would correspond to the assumption of McLaren (1986) according to which the structural growth rate becomes asymptotic at food levels that permit maximal development rates (here greater than $5 \mu g$-at. $\mathrm{N}^{-1}$ ).

Numerous studies have shown that nutritive preferences of copepods are various, with regard to both the diversity of available particles, and the selectivity of 
stages. We have assumed here that every stage can efficiently collect food particles. The real problem is to know if the particle spectrum measurable in the seawater is wide enough to provide each stage with its optimal food condition, so that individuals can grow exponentially. Since temperature acts on different stages following the same law, its influence is easier to study theoretically and experimentally.

Tande (1988) found a relation between temperature variation and mortality rate in Calanus finmarchicus. It would be interesting to determine how the metabolic rate varies in such conditions. Since the model is applicable for other crustaceans, more appropriate species than Euterpina acutifrons could be chosen, on which biological processes and dynamics are easier to measure.

The equiproportionality rule is applicable for species whose stage durations change in the same proportion as temperature varies (Corkett \& McLaren 1970, McLaren \& Corkett 1981, Corkett 1984, Corkett et al. 1986). Isochronality (Miller et al. 1977, Klein Breteler 1980) is a particular case of equiproportionality applicable to species whose stages have identical durations (Uye 1980, Landry 1983), and is not always observed (Landry 1983). Generally, equiproportionality is observed in well-fed animals. Our model demonstrates that this is also theoretically possible when food limits growth, and that equiproportionality is not restricted to saturating conditions of food. It confirms also the assumption of McLaren (1986) according to which equiproportionality and exponential structural growth are associated, if fixed structural molting weights are considered (Harris 1983)

Because physiological connections are numerous and non-linear, it is difficult to clearly discern the consequences induced by an hypothesis in relation to a given process. Deterministic models have 2 features: first, because individual variability is not taken into account, their results are not subject to variation; second, because of their associative structure, modifications performed on one of its components clearly influence the rest of the system. This study suggests that the $Q_{10}$ of ingestion, growth and development have to be determined simultaneously in experiments in order to compare them to the simulated values, respectively 2.6 , 3.47 and 3.48. The difference between ingestion and growth $Q_{10}$ values is surprising and interesting. It may be explained by the respresentation chosen for the influence of temperature on the processes involved in the nitrogen growth rate, and by the respective parts attributed to routine and active metabolism. In like manner, the similarity between $Q_{10}$ of growth and of development has to be verified experimentally for Euterpina acutifrons. Heinle (1969) observed that for Acartia tonsa the $Q_{10}$ of development and the $Q_{10}$ of growth are equal below $15^{\circ} \mathrm{C}$. Above, the growth $Q_{10}$ becomes lower than the development $Q_{10}$.

In the natural environment, variability of temperature and food induces complex responses in copepods which have to adapt in order to optimize their growth, reproduction and development. Their reaction in a fluctuating environment can be really understood only if the critical mechanisms stimulated by the perturbations are identified. Since several external factors vary simultaneously, and since biological processes are coupled by complex and non-linear interactions, it is not possible to predict easily the dynamics of a population without a conceptual structure which embodies the biological properties of copepods. Our model is a first step in this direction.

Empirical relationships traditionally used to represent the influences of food or temperature on development rate do not take into account intrinsic properties of animals, so their applications are limited. More especially, latency times are not reproduced by such models. It is clear that delays observed in physiological responses are of prime importance in population dynamics, since they may damp effects of external variations. We have represented very simply this faculty of living organisms, by considering that the cumulated specific growth rate averaged over a certain time interval was an appropriate criterion to represent the influence of growth rate on the molting process. It is clear that this representation is itself empirical. It could be refined by including in the model a supplementary variable representing internal storage. In any case, an interesting application of the model will be to see how population dynamics changes when the value of the cumulated time is modified. The more this value is increased, the more will high frequencies of variation be damped. This would permit evaluation of the robustness of the population development within several regimes of external fluctuations of food and temperature.

Acknowledgements. We thank Prof. P. Nival for discussions and criticisms of the manuscript.

\section{LITERATURE CITED}

Anger, $K$. (1987). The $D_{0}$ threshold: a critical point in the larval development of decapod crustaceans. J. exp. mar. Biol. Ecol. 108: 15-30

Anger, K., Spindler, K.-D. (1987). Energetics, moult cycle and ecdysteroid titers in spider crab (Hyas araneus) larvae starved after the $D_{0}$ threshold. Mar. Biol. 94: 367-375

Bartram, W. C. (1980). Experimental development of a model for the feeding of neritic copepods on phytoplankton. J. Plankton Res. 3: 25-51

Berggreen, U., Hansen, B., Kiorboe, T. (1988). Food size spectra, ingestion and growth of the copepod Acartia tonsa during development: implications for determination of copepod production. Mar. Biol. 99: 341-352 
Bernard, M. (1963). Le cycle vital en laboratoire dun copépode pélagique de Méditerranée Euterpina acutifrons Claus. Pelagos 1 (2): $35-48$

Burkill, P. H., Kendall, T F. (1982). Production of the copepod Eurytemora affinis in the Bristol channel. Mar Ecol. Prog. Ser. 7: 21-31

Carlotti, F. (1987). Modèles de recrutement de larves d'organismes marins. J. Rech. océanogr. 12: 12-16

Conover, R. J. (1966). Factors affecting the assimilation of organic matter by zooplankton and the question of superfluous feeding. Limnol. Oceanogr. 11: 346-354

Corkett, C. J. (1984). Observations on development in copepods. Studies on Copepoda II. Proceedings of the First International Conference on Copepoda, Amsterdam, 1981 Crustaceana, Suppl. 7: 150-153

Corkett, C. J., McLaren, I. A. (1969). Egg production and oil storage by the copepod $P_{\text {seudocalanus in the laboratory }}$ J. exp. mar. Biol. Ecol. 3: 90-105

Corkett, C. J., McLaren, I. A. (1970). Relationships between development rate of eggs and older stages of copepods. J. mar biol. Ass. U.K. 50: 161-168

Corkett, C. J., McLaren, I. A. (1978). Biology of Pseudocalanus. In: Russel, F. S. (ed.) Advances in marine biology, Vol. 15. Academic press, London, p. 1-233

Corkett, C. J., McLaren, I. A., Sevigny, F. M. (1986). The rearing of the marine calanoid copepods Calanus finmarchicus (Gunnerus), C. glacialis Jaschnov and C. hyperboreus Krøeyer with comment on the equiproportional rule (Copepoda). Syllogeus (Nat. Mus. Can.) 58: 539-546

Corner, E. D. S., Cowey, C. B., Marshall, S. M. (1967). On the nutrition and metabolism of zooplankton. $V$ Feeding efficiency of Calanus finmarchicus J. mar biol. Ass. U.K. 47 $259-270$

Dagg, M. J. (1977). Some effects of patchy food environments on copepods. Limnol. Oceanogr. 22: 99-107

D'Apolito, L. M., Stancyk, S. E. (1979). Population dynamics of Euterpina acutifrons (Copepoda, Harpacticoida) from North Inlet, South Carolina, with references to dimorphic males. Mar. Biol. 54: 251-260

Davis, C. S. (1984). Predatory control of copepod seasonal cycles on Georges Bank. Mar Biol. 82: 31-40

Durbin, E. G., Durbin, A. G. (1978). Length and weight relationships of Acartia clausi from Narragansett Bay, R. I. Limnol. Oceanogr 23: 958-969

Durbin, E. G., Durbin, A. G., Smayda, T J., Verity, P. G. (1983). Food limitation of production by Acartia tonsa in Narragansett Bay, Rhode Island. Limnol. Oceanogr 28: $1199-1213$

Fernandez, F. (1979). Nutrition studies in the nauplius larva of Calanus pacificus (Copepoda: Calanoida). Mar Biol. 53: $131-147$

Frost, B. W. (1972). Effects of size and concentration of food particles on the feeding behavior of the marine planktonic copepod Calanus pacjficus. Limnol. Oceanogr. 17: 805-815

Gaudy, R. (1974). Feeding four species of pelagic copepods under experimental conditions. Mar. Biol. 25: 125-141

Hamburger, K. Boetius, F. (1987). Ontogeny of growth, respiration and feeding rate of freshwater calanoid copepod Eudiaptomus graciloides, J. Plankton Res. 9: 589-606

Haq. S. M. (1965). Development of the copepod Euterpina acutifrons with special reference to dimorphism in the male. Proc. zool. Soc. Lond. 144: 175-201

Haq, S. M. (1972). Breeding of Euterpina acutifrons, a harpacticoid copepod, with special reference to dimorphic males. Mar. Biol. 15: 221-235

Haq, S. M. (1973). Factors affecting production of dimorphic males of Euterpina acutifrons. Mar. Biol. 19: 23-26.
Harpaz, S., Kahan, D., Galun, R. (1987). Variability in feeding behavior of the malaysian prawn Macrobrachium rosenbergii (DeMan) during the molt cycle (Decapoda, Caridea). Crustaceana 52: 53-60

Harris, R. P. (1983). The development and growth of Calanus copepodites. Limnol. Oceanogr 28: 142-147

Harris, R. P., Paffenhöfer, G.-A. (1976). Feeding, growth and reproduction of the marine planktonic copepod Temora longicornis Müller. J. mar biol. Ass. L'K. 56: 675-690

Heinle, D. R. (1969). Temperature and zooplankton. Chesapeake Sci. 10: 186-209

Heip, C. (1974). A comparison between models describing the influence of temperature on the development rate of copepods. Biol. Jb. Dodonaea 42: 121-125

Herman, P. M. J., Heip, C. (1985). Secondary production of the harpacticoid copepod Paronichocampus nanus in a brackish-water habitat. Limnol. Oceanogr. 30: 1060-1066

Huntley, M., Boyd, C. (1984). Food-limited growth of marine zooplankton. Am. Nat. 124: 455-478

Ikeda, T (1985). Metabolic rates of epipelagic marine zooplankton as function of both mass and temperature. Mar. Biol. 85: 1-11

Klein Breteler, W. C. M. (1980). Continous breeding of marine pelagic copepods in the presence of heterotrophic dinoflagellates. Mar Ecol. Prog. Ser. 2: 229-233

Kremer, J. N., Nixon, S. W (1978). A coastal marine ecosystem. Simulation and analysis. Ecological studies, Vol. 24. Springer-Verlag, Heidelberg

Lam, R. K., Frost, B. W (1976). Model of copepod filtering response to changes in size and concentration of food. Limnol. Oceanogr 21: 490-500

Landry, M. R. (1975). Seasonal temperature effects and predicting development rates of marine copepod eggs. Limnol. Oceanogr 20: 434-440

Landry, M. R. (1978). Population dynamics and production of a planktonic marine copepod, Acartia clausii, in a small temperate lagoon on San Juan Island, Washington. Int. Revue ges. Hydrobiol. 63: 77-119

Landry, M. R. (1983). The development of marine calanoid copepods with comments on the isochronal rule. Limnol. Oceanogr. 28: 614-624

Lasker, R. (1966). Feeding, growth, respiration and carbon utilization of a euphausijd crustacean. J. Fish. Res. Bd Can. 23: $1291-1317$

Lehman. J. T. (1976). The filter-feeder as an optimal forager and the predicted shapes of feeding curves. Limnol. Oceanogr. 21: 501:516

Marshall, S. M. (1973). Respiration and feeding in copepods. In: Russel, F. S. (ed.) Advances in marine biology, Vol 11. Academic press, London, p. 57-120

McLaren, I. A. (1963). Effects of temperature on growth of zooplankton and the adaptive value of vertical migration. J. Fish. Res. Bd Can. 20: 685-727

McLaren, I. A. (1978). Generation lengths of some temperate marine copepods: estimation, production and implications. J. Fish. Res. Bd Can. 345: 1330-1342

McLaren, I. A. (1986). Is "structural" growth of Calanus potentially exponential? Limnol. Oceanogr. 31: 1342-1346

McLaren, I. A., Corkett, C. J. (1981). Temperature-dependent growth and production by a marine copepod Can. J. Fish. Aquat. Sci. 38: 77-83

Miller, C. A., Landry, M. R. (1984). Ingestion-independent rates of ammonium excretion by the copepod Calanus pacificus. Mar. Biol 78: 263-270

Miller, C. B., Huntley, M. E., Brooks, E. R. (1984). Postcollection molting rates of planktonic marine copepods: 
measurement, applications, problems. Limnol. Oceanogr. 29: $1274-1289$

Miller, C. B., Johnson, J. K., Heinle, D. R. (1977). Growth rules in the marine copepod genus Acartia. Limnol. Oceanogr 22: $326-335$

Moreira, G. S. (1975). Studies on the salinity resistance of the copepod Euterpina acutifrons (Dana). In: Vernberg, F. J. (ed.) Physiological ecology of estuarine animals. Univ. of South Carolina Press, Columbia, p. 73-79

Moreira, G. S., Vernberg, W. B. (1968). Comparative thermal metabolic patterns in Euterpina acutifrons dimorphic males. Mar. Biol. 1: 282-284

Moreira, G. S., Vernberg, W. B. (1978). Synergistic effects of environmental variables on the metabolism of the copepod Euterpina acutifrons from two different areas off the coast of the state of Sao Paulo, Brasil. Fish. Bull. U.S. 76: 449-455

Moreira, G. S., Vernberg, W. B., Jackson, K. (1985). Comparative studies on the metabolism of Euterpina acutifrons (Dana) (Copepoda, Harpacticoida): temperature and salinity effects in copepods from Georgetown, South Carolina. Bull. mar. Sci. 37 (2): 691-696

Mullin, M. M., Brooks, E. R. (1970a). Growth and metabolism of two planktonic marine copepods as influenced by temperature and two types of food. In: Steele, J. H. (ed.) Marine food chains. Oliver \& Boyd, Edinburgh, p. 74-95

Mullin, M. M., Brooks, E. R. (1970b). The effect of concentration of food on body weight, cumulative ingestion and rate of growth of the marine copepod, Calanus helgolandicus. Limnol. Oceanogr. 15: 748-755

Nassogne, A. (1969). The culture of copepods in the laboratory. Pubbl. Staz. zool. Napoli 37: 203-218

Nassogne, A. (1970). Influence food organisms on the development and culture of pelagic copepods. Helgoländer wiss. Meeresunters. 20: 333-345

Neunes, H. W., Pongolini, G.-F. (1965). Breeding a pelagic copepod Euterpina acutifrons (Dana) in the laboratory. Nature, Lond. 208: 571-573

Nival, P., Carlotti, F., Sciandra, A. (1988). Modelling of recruitment of marine species. In: Rothshild, B. J. (ed.) Toward a theory of biological-physical interactions in the world ocean. NATO series in marine sciences, Kluwer Academic Publisher, Dordrecht, p. 321-342

Nival, P., Malara, G., Charra, R., Palazzoli, I., Nival, S. (1974). Etude de la respiration et de l'excrétion de quelques copépodes planctoniques (Crustacea) dans la zone de la remontée d'eau profonde des côtes marocaines. J. exp. mar Biol. Ecol. 15: 231-260

Paffenhöfer, G.-A. (1970). The cultivation of Calanus helgolandicus under controlled conditions. Helgoländer wiss. Meeresunters. 20: 346-359

Paffenhöfer, G.-A. (1971). Grazing and ingestion rates of nauplii, copepodids and adults of the marine planktonic copepod Calanus helgolandicus. Mar. Biol. 11: 286-298

Paffenhöfer, G.-A., Harris, R. P. (1976). Feeding, growth and reproduction of the marine planktonic copepod Pseudocalanus elongatus Boeck, J. mar. biol. Ass. U. K. 56: 327-344

Paffenhöfer, G.-A., Harris, R. P. (1979). Laboratory culture of marine holozooplankton and its contribution to studies of marine planktonic food webs. In: Russel, F. S. (ed.) Advances in marine biology, Vol. 16. Academic Press, London, p. 211-308

Razouls, C., Razouls, S. (1976). Dimensions, poids secs valeurs calorifiques et courbes de croissances de deux populations naturelles de copépodes planctoniques de Méditerranée. Vie Milieu 26: 281-297

Sciandra, A. (1982). Etude d'un écosystème marin artificiel: construction d'un modèle et application à l'exploitation d'un copépode pélagique Euterpina acutifrons Dana. Thèse 3ème cycle, Océanographie Biologique, Université Paris VI

Sciandra, A. (1986a). Study and modelling of development of Euterpina acutifrons (Copepoda, Harpacticoida). J. Plankton Res. 8: 1149-1162

Sciandra, A. (1986b). Study and modelling of a simple planktonic system reconstituted in an experimental microcosm. Ecol. Modelling 34: 61-82

Sekiguchi, H., McLaren, I. A., Corkett, C. J. (1980). Relationship between growth rate and egg production in the copepod Acartia clausi Hudsonica. Mar. Biol. 58: 133-138

Skinner, D. M. (1985a). Molting and regeneration. In: Bliss, D. E., Mantel, L. H. (eds.) The biology of Crustacea, Vol. 9. Academic Press, New York

Skinner, D. M. (1985b). Interacting factors in the control of the crustacean molt cycle. Am. Zool. 25: 275-284

Smith, S. L., Lane, P. V Z. (1985). Laboratory on the marine copepod Centropages typicus, egg production and development rates. Mar. Biol. 85: 153-162

Steele, J. H. (1974). The structure of marine ecosystem. Harvard University Press Cambridge

Steele, J. H., Frost, B. W. (1977). The structure of plankton communities. Phil. Trans. R. Soc. (Ser. B) 280: 485-534

Steele, J. H., Mullin, M. M. (1977). Zooplankton dynamics. In: Goldberg, E. D., McCave, 1. N., O'Brien, J. J., Steele, J. H. (eds.) The seas, Vol. 6. John Wiley \& Son, New York, p. $857-890$

Sulkin, S. D., Van Heukelem, W F. (1986). Variability in the length of the megalopal stage and its consequences to dispersal and recruitment in the portunid crab Callinectes sapidus Rathbun. Bull. mar. Sci. 39: 269-278

Sushchenya, L. M. (1970). Food rations, metabolism and growth of Crustaceans. In: Steele, J. H. (ed.) Marine food chains. Oliver \& Boyd, Edinburgh, p. 127-141

Tande, K. S. (1988). Aspects of developmental and mortality rates in Calanus finmarchicus related to equiproportional development. Mar Ecol. Prog. Ser. 44: 51-58

Tessier, A. J., Goulden, C. E. (1987). Cladoceran juvenile growth. Limnol. Oceanogr. 32: 680-686

Thompson, B. M. (1982). Growth and development of Pseudocalanus elongatus and Calanus sp. in the laboratory. J. mar. biol. Ass. U.K. 62: 359-372

Uye, S. (1980). Development of neritic copepods Acartia clausi and $A$. steueri. II. Isochronal larval development at various temperatures. Bull. Plankton Soc. Japan 27: 11-18

Uye, S. (1981). Fecundity studies of neritic calanoid copepod Acartia clausi Giesbrecht and A. steueri Smirnov: a simple empirical model of daily egg production. J. exp. mar. Biol. Ecol. 50: 255-271

Vernberg, W. B., Moreira, G. S. (1974). A mebabolic-temperature response of the copepod Euterpina acutifrons (Dana) from Brazil. Comp. Biochem. Physiol. 49a: 757-761

Vernberg, W. B., Moreira, G. S. (1981). Thermal adaptations of latitudinally separated populations of the copepod Euterpina acutifrons. Bull mar. Sci. 31: 815

Vidal, J. (1980a). Physioecology of zooplankton. I. Effects of phytoplankton concentration, temperature, and body size on the growth rate of Calanus pacificus and Pseudocalanus sp. Mar. Biol. 56: 111-134

Vidal, J. (1980b). Physioecology of zooplankton. II. Effects of phytoplankton concentration, temperature and body size on the development and molting rates of Calanus pacificus and Pseudocalanus sp. Mar. Biol. 56: 135-146

Vidal, J. (1980c). Physioecology of zooplankton. III. Effects of phytoplankton concentration, temperature, and body size 
on the metabolic rate of Calanus pacificus. Mar. Biol. 56: 195-202

Weglenska, $T$ (1971). The influence of various concentrations of natural food on the development, fecundity and production of planktonic crustacean filtrators. Ekol. pol. 30: $427-471$

Wroblewski, J. S. (1980). A simulation of the distribution of Acartia clausi during the Oregon Upwelling, August 1973. J. Plankton Res. 2: 43-68

Wroblewski, J. S. (1984). Formulation of growth and mortality of larvae northern anchovy in a turbulent feeding environment. Mar. Ecol. Prog. Ser. 20: 13-22

This article was submitted to the editor
Wroblewski, J. S., Richman, J. G. (1987). The non-linear response of plankton to wind mixing events - implications for survival of larval northern anchovy. J. Plankton Res. 9: 103-123

Yassen, S. (1979). Essai sur la production et la dynamique de population d'un copépode planctonique Euterpina acutifrons. Thèse de 3ème cycle. Université Paris VI

Zurlini, G., Ferrari, I. (1979). Growth of marine copepod population in excess food supply. Boll. Zool. 46: 225-228

Zurlini, G., Ferrari, I., Nassogne, A. (1978). Reproduction and growth of Euterpina acutifrons (Copepoda. Harpacticoida) under experimental conditions. Mar. Biol. 46: 59-64

Manuscript first received: August 29, 1988

Revised version accepted: May 18, 1989 